\title{
STUDY ON ANTI-MICROBIAL PROPERTIES OF Enicosanthum membranifolium SINCLAIR AND Enicosanthum cupulare (KING) AIRY-SHAW
}

\author{
Mai Efdi ${ }^{1}$, Mamoru Koketsu ${ }^{2}$, Kunitomo Watanabe ${ }^{3}$, Nurainas ${ }^{4}$ \\ ${ }^{1}$ Department of Chemistry, Faculty of Mathematics and Natural Science, Andalas University \\ ${ }^{2}$ Division of Instrumental Analysis, Life Science Research Center \\ ${ }^{3}$ Division of Anaerobe Research Life Science Research Center, Gifu University \\ ${ }^{4}$ Department of Biology, Faculty of Mathematics and Natural Science, Andalas University
}

\begin{abstract}
$n$-Hexane and ethyl acetate fractions of methanol extracts of two species of Annonaceae, Enicosanthum membranifolium Sinclair and Enicosanthum cupulare (King) Airy-Shaw, were screened for antimicrobial activity against eighteen bacterial strains using agar dilution method. The ethyl acetate fraction of the two Annonaceae plants showed higher antimicrobial activities than the $n$-hexane fraction. The extracts of the plants tested were significantly more active against grampositive with minimum inhibitory concentration (MICs) ranging from 0.0625 to $4 \mathrm{mg} / \mathrm{mL}$ than against gram negative bacteria (MICs $>4 \mathrm{mg} / \mathrm{mL}$ ).
\end{abstract}

Keywords: Antibacterial activity; Enicosanthum membranifolium Sinclair; Enicosanthum cupulare (King) Airy-Shaw

\section{INTRODUCTION}

Many efforts have been made to discover new antimicrobial compounds from various kinds of sources such as micro-organisms, animals, and plants. Numerous studies have been carried out to extract various natural products for screening antimicrobial activity ${ }^{[1-5]}$. Systematic screening of them may result in the discovery of novel effective compounds ${ }^{[6]}$. Annonaceae family is one of the plants which attracted much interest. Annonaceae family is a rich source of bioactive substances. Many species belonging to Annonaceae family produced antimicrobial compounds with structurally diverse. $C$-Benzylated chalcone was isolated from Ellipeiopsis cherrevensis ${ }^{[7]}$. Mitrephorone A, mitrephorone B and mitrephorone were isolated from Mitrephora glabra $^{[8]}$. Reticuline, anonaine, laurelliptine and isoboldine were found in the bark of Annona salzmanii D.C. ${ }^{[9]}$. Cherimolin and dihydrocherimolin were obtained in Annona cherimolia $^{[10]}$. Ent-trachyloban-19-oic acid, ent-kaur-16-en-19-oic acid, 8(14),15pimaradien-18-oic acid and 7,15-pimaradien18-oic acid were identified in Mitrephora celebica $^{[11]}$.
Therefore, in order to confirm value of Annonaceae plants four species belonging this family was collected in Rimbo Panti forest; they are Enichonsanthum membranifolium Sinclair, Enichonsanthum cupulare (King) Airy-Shaw. Based on preliminary screening, these species showed antimicrobial activities. As a part of our study on Annonaceae plants grown in West Sumatra, in this paper we wish to report screening of anti-microbial activities of Enicosanthum membranifolium Sinclair and Enicosanthum cupulare (King) Airy-Shaw.

\section{MATERIALS AND METHODS}

\section{Plants Materials and Extract Preparation}

Enicosanthum membranifolium Sinclair, Enicosanthum cupulare (King) Airy-Shaw and Polyalthia cauliflora var. desmantha (Hk. f. et Th.) Sinclair used in this study were collected in Rimbo Panti forest, West Sumatra, Indonesia Voucher specimen are deposited at Herbarium Andalas University (AND), Padang, Indonesia.

Air dried plant materials were finely ground 
and macerated at room temperature in methanol. The extract was subsequently filtered and concentrated in vacuo. Each methanol extract of the plants was partitioned successively with $n$-hexane, ethyl acetate, $n$ butyl alcohol and water. Then each fraction ( $n$ hexane, ethyl acetate, $n$-butyl alcohol and water) was evaporated in vacuo and tested for antimicrobial activity.

\section{Antimicrobial Screening}

\section{Micro-Organisms}

The following strains of microorganisms were used: Bacillus cereus, Bacillus subtilis, Streptococcus pyogenes, Staphylococcus epidermis, Staphylococcus aureus, Streptococcus agalactiae, Streptococcus salivarius, Enterococus faecalis, Salmonella sp., Vibrio parahaemolyticus, Yersinia enterocolitica, Pseudomonas aeruginosa, Klebsiella pneumoniae, Achromobacter xylosoxidans, Enterobacter aerogenes, Escherichia coli, Candida albicans and Candida sp.

\section{Preliminary Screening for Antimicrobial Activities}

Plate diffusion assay (cup method) was performed for preliminary screening of methanol extracts and four fractions ( $n$-hexane, EtOAc, $n$-butanol and water) of Eniconsanthum membranifolium Sinclair, Enichonsanthum cupulare (King) Airy-Shaw and Polyalthia cauliflora var. desmantha (Hk. f. et Th.) Sinclair. The antimicrobial assay was carried out based on an NCCLS global consensus standard ${ }^{[12]}$. In this method, Staphylococcus aureus and Bacillus subtilis were used as test organisms. The dried plant extracts were dissolved in aqueous dimethylsulfoxide (DMSO) : water (125: 875) to a final concentration of $10 \mathrm{mg} / \mathrm{L}$. Sterile cups were placed on the surface of agar plates inoculated with a microbial culture and then $200 \mu \mathrm{L}$ of the solution extracts were dropped into the cups. Each extract was tested in duplicate. Control cup contained $200 \mu \mathrm{L}$ of sterile $12.5 \%$ aqueous DMSO. Agar plates containing bacteria were incubated at $35^{\circ} \mathrm{C}$ for $24 \mathrm{~h}$. After incubation, the diameters of growth inhibition zones around the cups were measured.

\section{Minimum Inhibitory Concentration (MIC)}

In vitro antimicrobial activity was determined by the agar dilution method. The antimicrobial assay was carried out based on an NCCLS global consensus standard ${ }^{[13]}$. A series of concentrations $(4,2,1,0.5,0.25,0.125,0.0625$ $\mathrm{mg} / \mathrm{mL}$ ) from extracts were prepared in $1 \mathrm{~mL}$ DMSO. Each antimicrobial dilution $(0.2 \mathrm{~mL})$ was transferred to a tube containing $19.8 \mathrm{~mL}$ of BHI medium to make a 1:10 dilution. Then it was mixed well and poured into a Petri dish. It was allowed to set and dry the surface of the plates. Suspensions of microorganisms were then incubated on the plate containing of antimicrobial compounds at $35^{\circ} \mathrm{C}$ for $18 \mathrm{~h}$. Control (just containing solvent only) was made with the same ways. Polyphenon- 100 (containing epigallocatechin gallate 59.4\%, epigallocatechin $11.6 \%$, epicatechin $11.4 \%$, epicatechin gallate $2.1 \%$ and gallocatechin gallate $4.3 \%$ ) as positive control was made in the same ways. The MIC was determined as the lowest dilution which completely prevented microbial growth.

\section{Phytochemical Screening}

Identifications of secondary metabolites were carried out on the methanol extract of the plants using chemical method according to the methods described by Fransworth ${ }^{[14]}$ and Harbone ${ }^{[15,16]}$.

\section{RESULT AND DISCUSSION}

Screening of antimicrobial activity of methanol extracts of Enicosanthum membranifolium Sinclair and Enicosanthum cupulare (King) Airy-Shaw against Staphyllococcus aureus and Bacillus subtilis was carried out using cup method. All of methanol extracts showed activities against the microorganism tested. Inhibitory zone of Enicosanthum membranifolium Sinclair methanol extract was $18.3 \mathrm{~mm}$ (B. subtilis) and $12.2 \mathrm{~mm}$ (S. aureus). The inhibitory zone of Enicosanthum cupulare (King) Airy-Shaw was $25.7 \mathrm{~mm}$ (B. subtilis) and $9.98 \mathrm{~mm}$ ( $S$. aureus). The $n$-hexane, ethyl acetate, $n$ - butanol and water fractions of their 
extracts were tested their antimicrobial activity using cup method against $S$. aureus and $B$. subtilis. As the results the $n$-hexane and ethyl acetate fractions showed activity against microorganism tested (Table 1). The $n$-hexane and ethyl acetate fractions of each species were necessary to be continued to evaluate their potential as antimicrobial. To study their antimicrobial activities, 18 kinds of strain microorganisms were used.

Table 2 shows the MICs of the extracts tested (range of concentration of crude extracts: 0.0625 to $4 \mathrm{mg} / \mathrm{mL}$ ) against a range of microorganisms. The extracts of the plant mainly inhibited against gram-positive microorganisms. Against bacterial Grampositive, the activities of ethyl acetate fraction of Enicosanthum membranifolium Sinclair, Enicosanthum cupulare (King) Airy-Shaw and Polyalthia cauliflora var. desmantha Sinclair were stronger than $n$-hexane fractions. The $n$ hexane extract of $E$. membranifolium was active against $B$. subtilis, $S$. pyogenes and $E$. faecalis (gram-positive microorganisms) with range of MICs were 0.5 to $2 \mathrm{mg} / \mathrm{mL}$.

The ethyl acetate fraction of this plant was active against $B$. cereus, $B$ subtilis, $S$. pyogenes, $S$. epidermis, $S$. aureus, $S$. agalactiae and $S$. salivarius (gram-positive microorganisms) with 0.0625 to $1 \mathrm{mg} / \mathrm{mL}$ of MICs range. The nhexane extract of $E$. cupulare was active against B. cereus, B. subtilis, S. pyogenes, $S$. epidermis, $S$. aureus, $S$. agalactiae and $S$. salivarius with MICs range were 0.25 to 1 $\mathrm{mg} / \mathrm{mL}$. MICs range of the ethyl acetate extracts of this plant against $B$. cereus, $B$ subtilis, $S$. pyogenes, $S$. epidermis, $S$. aureus, $S$. agalactiae and $S$. salivarius were $<0.0625$ to 1 $\mathrm{mg} / \mathrm{mL}$. The $n$-hexane and ethyl acetate extracts of $P$. cauliflora were active against $B$. cereus, B. subtilis, S. pyogenes, S. epidermis and $S$. aureus with range of MICs were 1-2 $\mathrm{mg} / \mathrm{mL}$ and $<0.0625$ to $0.25 \mathrm{mg} / \mathrm{mL}$. Most of the extracts showed no inhibitory activity against Salmonella sp., Yersinia enterocolitica, Achromobacter xylosoxidans, Enterobacter aerogenes, Escherichia coli, Candida albicans and Candida sp $(>4 \mathrm{mg} / \mathrm{mL})$. Anti-fungal activity was tested using Candida albicans and Candida sp, most of the extract showed no significant inhibitory activity $(>4 \mathrm{mg} / \mathrm{mL})$.

The freshly leaves of Enicosanthum membranifolium Sinclair and Enicosanthum cupulare (King) Airy-Shaw were subjected to preliminary phytochemical screening. The results showed the presence of phenolic, steroid, terpenoid and alkaloid in two plant leaves (Table 3). The test for flavonoid, however, showed negative result. The presence of secondary metabolites such as phenolics, steroid, terpenoid and alkaloid in these plants could be responsible for antimicrobial activity, because many compounds from these classes have reported as antimicrobial agents.

Table 1. Antimicrobial Activities of $\boldsymbol{n}$-Hexane, Ethyl Acetate, $\boldsymbol{n}$-Butanol and Water Fractions of Three Annonaceae Species

\begin{tabular}{lllll}
\hline No & Plants & Fraction & \multicolumn{2}{c}{ Inhibitory zone (mm) } \\
\cline { 4 - 5 } & & Bacillus subtilis & $\begin{array}{l}\text { Staphylococcus } \\
\text { aureus }\end{array}$ \\
\hline 1 & Enicosanthum & $n$-Hexane & 20.5 & 15.3 \\
& membranifolium & Ethyl acetate & 15.11 & 15.3 \\
& Sinclair & $n$-Butanol & NA & NA \\
& & Water & NA & NA \\
\hline 2 & Enicosanthum & $n$-Hexane & 14.3 & 13.0 \\
& cupulare & Ethyl acetate & 24.1 & 16.8 \\
& & n-Butanol & NA & NA \\
& Water & NA & NA \\
& & Ethyl acetate & 18.8 & 11.0 \\
& $n$-Butanol & NA & NA \\
& & Nater & & NA \\
\hline
\end{tabular}


Table 2. MIC of $n$-Hexane and Ethyl Acetate Fractions of Enicosanthum membranifolium Sinclair and Enicosanthum cupulare Against 18 Kinds of Microorganisms

\begin{tabular}{|c|c|c|c|c|c|c|}
\hline \multirow[t]{3}{*}{ No } & \multirow[t]{3}{*}{ Microorganisms } & \multicolumn{4}{|c|}{ Antimicrobial activity $(\mathrm{mg} / \mathrm{mL})$} & \multirow{3}{*}{$\mathrm{P}$} \\
\hline & & \multicolumn{2}{|c|}{ EmS } & \multicolumn{2}{|c|}{$\mathrm{EcS}$} & \\
\hline & & Hex & EtOAc & Hex & EtOAc & \\
\hline & $\begin{array}{ll}\text { Gram-positive } & \text { spore forming } \\
\text { rods }\end{array}$ & & & & & \\
\hline 1. & Bacillus cereus & 4 & 0.25 & 0.5 & 0.125 & 0.125 \\
\hline \multirow[t]{2}{*}{2.} & Bacillus subtilis & 0.5 & 0.0625 & 0.25 & $<0.0625$ & 0.5 \\
\hline & $\underline{\text { Gram-positive cocci }}$ & & & & & \\
\hline 3. & Streptococcus pyogenes & 2 & 0.5 & 0.5 & 0.125 & 0.25 \\
\hline 4. & Staphylococcus epidermis & $>4$ & 1 & 1 & 0.25 & $<0.0625$ \\
\hline 5. & Staphylococcus aureus & $>4$ & 0.5 & 0.5 & 0.25 & 0.125 \\
\hline 6. & Streptococcus agalactiae & $>4$ & 0.25 & 0.25 & 0.5 & 0.5 \\
\hline 7 & Streptococcus salivarius & $>4$ & 1 & 1 & 0.25 & 0.5 \\
\hline \multirow[t]{2}{*}{8} & Enterococcus faecalis & 2 & $>4$ & $>4$ & 1 & 1 \\
\hline & $\underline{\text { Gram-negative rods }}$ & & & & & \\
\hline 9. & Salmonella sp. & $>4$ & $>4$ & $>4$ & $>4$ & 0.5 \\
\hline 10. & Vibrio parahaemolyticus & $>4$ & 2 & $>4$ & $>4$ & 0.125 \\
\hline 11 & Yersinia enterocolitica & $>4$ & 2 & $>4$ & $>4$ & 0.25 \\
\hline 12 & Pseudomanas aeruginosa & $>4$ & $>4$ & $>4$ & $>4$ & 0.5 \\
\hline 13 & Klebsiella pneumoniae & $>4$ & $>4$ & $>4$ & $>4$ & 1 \\
\hline 14. & Achromobacter xylosoxidans & $>4$ & 2 & $>4$ & $>4$ & 0.125 \\
\hline 15 & Enterobacter aerogenes & $>4$ & $>4$ & $>4$ & $>4$ & 1 \\
\hline \multirow[t]{2}{*}{16.} & Escherichia coli & $>4$ & $>4$ & $>4$ & $>4$ & 1 \\
\hline & $\underline{\text { Yeast }}$ & & & & & \\
\hline 17. & Candida albicans & $>4$ & $>4$ & $>4$ & $>4$ & 0.125 \\
\hline 18. & Candida sp. & $>4$ & $>4$ & $>4$ & $>4$ & 0.125 \\
\hline
\end{tabular}

EmS: Enicosanthum membranifolium Sinclair; EcS: Enicosanthum cupulare; P: Polyphenon-100 (as positive control)

Table 3. Phytochemical Analysis of Enicosanthum membranifolium, Enicosanthum cupulare, Polyalthia cauliflora var. desmantha and Goniothalamus tapis Miq

\begin{tabular}{llcc}
\hline \multirow{2}{*}{ Principles } & Test applied & \multicolumn{2}{c}{ Plants } \\
\cline { 2 - 4 } & Mayer & EmS & EcS \\
Alkaloids & Ferric & + & + \\
componolic & chloride & + & + \\
Flavonoids & $\mathrm{Mg} / \mathrm{HCl}$ & & - \\
Terpenoids/steroids & $\mathrm{H}_{2} \mathrm{SO}_{4}-\mathrm{Ac}_{2} \mathrm{O}$ & - & + \\
EmS: Enicosanthum membranifolium; EcS: Enicosanthum cupulare & & +
\end{tabular}




\section{CONCLUSION}

In conclusion, the three Annonaceae species used in this study exhibited selective antimicrobial activity to varying degrees. They may, therefore, provide new leads in the ongoing search for novel antimicrobial drugs. Bioassay-guided isolation of the antimicrobial active compounds will be made on the active fractions of E. membranifolium Sinclair, E. cupulare (King) Airy-Shaw and Polyalthia cauliflora var. desmantha (Hk. f. et Th.) Sinclair. We also aim to perform chemical characterization of some of the antimicrobially active compounds.

\section{ACKNOWLEDGEMENTS}

We thank to Pitra Akhriadi S.Si of herbarium Andalas University (AND) for helping in the collection and identification of the plant materials.

\section{REFERENCES}

1. C. M. Chariandy, C. E. Seaforth, R. H. Phelps, G. V. Pollard, B. P. S. Khambay, J. Ethnopharmacol., 64: 265-270, (1999).

2. P. Kloucek, Z. Polesny, B. Svobodova, E. Vlkova, L. Kokoska, J. Ethnopharmacol, 99: 309-312, (2005).

3. J. B. Sindambiwe, M. Calomme, P. Cos, J. Totté, L. Pieters, A. Vlietinck, D. V. Berghe, J. Ethnopharmacol, 65: 71-77, (1999).

4. G. H. Konning, C. Agyare, B. Ennison, Fitoterapia, 75: 65-67, (2004).

5. I. Ahmad, Z. Mehmood, F. Mohammad, J. Ethnopharmacol, 62: 183-193, (1998).
6. T. Nitta, T. Arai, H. Takamatsu, Y. Inatomi, H. Murata, M. Iinuma, T. Tanaka, T. Ito, F. Asai, I. Ibrahim, T. Nakanishi, K. Watanabe, J. Health Sci., 48: 273-276, (2002).

7. L. Wirasathien, T. Pengsuparp, M. Moriyasu, K. Kawanishi, R. Suttisri, Arch. Pharmacal. Res., 29: 497-502, (2006).

8. C. Li, D. Lee, T. N. Graf, S. S. Phifer, Y. Nakanishi, J. P. Burgess, S. Riswan, F. M. Setyowati, A. M. Saribi, D. D. Soejarto, N. R. Farnsworth, J. O. Falkinham, D. J. Kroll, A. D. Kinghorn, M. C. Wani, N. H. Oberlies, Org. Lett., 7: 5709-5712, (2005).

9. M. de Q. Paulo, J. M. Barbosa-Filho, E. O. Lima, R. F. Maia, de R. Cassia, B. B. C. Barbosa, M. A. C. Kaplan, $J$. Ethnopharmacol, 36: 39-41, (1992).

10. D. Cortes, J. L. Rios, A. Villar, S. Valverde, Tetrahedron Lett., 25: 3199 3202, (1984).

11. J. R. Zgoda-Pols, A. J. Freyer, L. B. Killmer, J. R. Porter, Fitoterapia, 73: 434438, (2002).

12. An NCCLS global consensus standard, Performance standards for antimicrobial disk susceptibility tests: Approved standard Eight edition, 2003, 6-11.

13. An NCCLS global consensus standard, Methods for dilution antimicrobial susceptibility tests for bacteria that grow aerobically: Approved standard, Sixth edition, 2003, 9-13.

14. N. R. Fransworth, J. Pharm. Sci., 55: 225276, (1966).

15. J. B. Harborne, Phytochemical Method. Chapmann and Hall, London, 1973.

16. J. B. Harborne, Phytochemical methods. In: A Guide to Modern Technique of Plant Analysis, second ed. Chapmann and Hall, London, 1984, 192. 